\section{BMJ Health \& Care Informatics}

\title{
Trend of intestinal infectious diseases recorded at a tertiary care hospital in India: an ICD-10 analysis
}

\author{
P N Roopalekha Jathanna, ${ }^{1}$ Ramya Vijeta, ${ }^{2}$ Vinod R Jathanna ${ }^{3}$
}

To cite: Jathanna PNR, Vijeta R, Jathanna VR. Trend of intestinal infectious diseases recorded at a tertiary care hospital in India: an ICD-10 analysis. BMJ Health Care Inform 2019;26. doi:10.1136/ bmjhci-2019-000021

Received 23 November 2018 Revised 05 March 2019 Accepted 13 March 2019

\section{Check for updates}

(c) Author(s) (or their employer(s)) 2019. Re-use permitted under CC BY-NC. No commercial re-use. See rights and permissions. Published by BMJ.

${ }^{1}$ Department of Health Information Management, School of Allied Health Sciences, Manipal Academy of Higher Education, Manipal, India ${ }^{2}$ Department of Orthodontics and Dentofacial Orthopaedics, Manipal College of Dental Sciences, Manipal Academy of Higher Education, Manipal, India ${ }^{3}$ Department of Conservative Dentistry and Endodontics, Manipal College of Dental Sciences, Manipal Academy of Higher Education, Mangalore, India

Correspondence to P N Roopalekha Jathanna; roopa.jathanna@manipal.edu

\section{ABSTRACT}

The World Health Organization identifies the leading cause of morbidity and mortality in developing countries as infectious and communicable diseases. Health records coded uniformly using ICD-10 can form an accurate database and conclusions drawn from this are extremely important for understanding the public health situation. The aim of this study is to analyse the trend of intestinal infectious diseases recorded at a tertiary care hospital in India.

A retrospective disease index study was conducted on data comprising 5317 cases from 2012 to 2016 for intestinal infectious diseases, analysed with ICD-10. Of these, $5.5 \%$ were from the age group $0-5$ years; $57.66 \%$ were male; and $85 \%$ deaths in this cohort $(62 / 73)$ were due to diarrhoea and gastroenteritis of presumed infectious origin.

The findings of this study highlight an urgent need for health education among the population regarding infectious intestinal diseases and to redesign health promotion and preventive strategies for addressing these problems.

\section{INTRODUCTION}

It is said that early identification and detection of infectious diseases in a region is necessary for appropriate measures of control and prevention. ${ }^{1}$ In the $1990 \mathrm{~s}$, the World Health Organization (WHO) facilitated the growth of disease surveillance programme in developed and underdeveloped countries based on the evidence. ${ }^{2}$ One important evidence source is the disease indices maintained by hospitals.

The common causes for hospital admission in India are infectious and communicable diseases, although there is a significant increase in lifestyle-related and non-communicable diseases. According to WHO, ${ }^{3}$ although there is economic growth and development in its member states, the growth in the detection and control of infectious and communicable diseases is slow. WHO also reports ${ }^{2}$ that the leading cause of morbidity and mortality in member states is infectious and communicable disease. It suggests that hospital records
Summary

What is already known?

- Standard health reporting system plays significant role in the health status of any region, state or country.

- WHO's International Statistical Classification of Diseases and Related Health Problems (ICD-10) is a standard tool for health reporting and research.

What does this paper add?

- In much prevalent intestinal infectious diseases, ICD -10 analysis showed, more than two thirds as diarrhoeas and gastroenteritis.

- Aetiology of diarrhoeas and gastroenteritis were not specified in any of the cases as they were recorded as "presumed to be infectious" or "unspecified".

- Need for more community health education programs in the region to bring down the much prevalent infectious intestinal diseases in the region.

- Health administrators/decision makers should come up with policies to implement and monitor standard documentation practice and accurate reporting system in the country.

should be coded uniformly using the International Statistical Classification of Diseases and Related Health Problems (ICD-10) to build a database. The conclusions that can be drawn from the analysed information is extremely important for understanding the public health situation of the country. More than 100 countries use ICD to report mortality data. This reporting system helps to monitor death and disease rates worldwide and measure progress towards the Sustainable Development Goals (Goal 3.3). ${ }^{4}$

In India, the majority of hospitals still use manual medical records and coding is still not a routine practice. Although the Ministry of Health and Family Welfare suggested the implementation of electronic health records (EHR) and ICD-10 system of reporting, many hospitals including public healthcare centres have not yet initiated the process. Various studies related to communicable diseases and non-communicable 


\section{AGE GROUP TREND ANALYSIS}

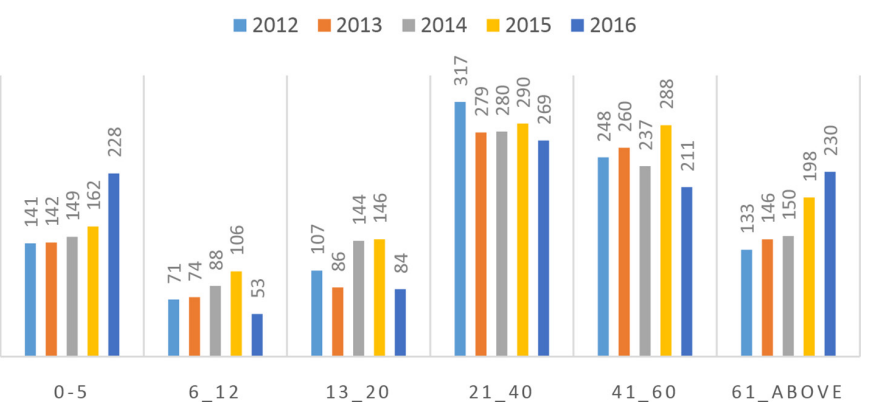

Figure 1 Age group analysis of intestinal infectious diseases from 2012 to 2016.

diseases have been conducted in different states and regions of India and have projected the prevalence of infectious diseases based on limited sources of information. In recent years, few of the corporate hospitals and private teaching hospitals have transitioned to electronic health records including the current study setting. There is no previous Indian study related to the prevalence of intestinal infection diseases based on ICD-10 classification. Informed policy-making requires accurate information about incidence, prevalence, aetiology and trend of infectious diseases, as it can support the development of preventive strategies.

\section{AIM}

To study the trend of intestinal infectious diseases recorded at a tertiary care hospital in India.

\section{MATERIAL AND METHODS}

The study was carried out in a 2032-bedded tertiary care teaching hospital in a coastal state of India with an approximate catchment area of $450 \mathrm{~km}^{2}$. A retrospective disease index study was carried out for a 5-year period from 2012 to 2016. Data was extracted from the disease index. Three-disease coding policy is followed in the hospital for primary, secondary and tertiary diagnosis. Diagnosis is coded with ICD-10. For the current study, Block A00 to A09 for intestinal infectious diseases was selected. The total sample size was 5317.

SPSS version 20 was used to calculate frequencies and percentiles. The study was carried out with approval from the Institutional ethical committee.

\section{RESULTS}

The total number of intestinal infectious diseases indexed from 2012 to 2016 was 5317. Of the total 5317 cases, $57.66 \%$ (3066) were male and $42.34 \%$ (2251) were female. The trend showed consistently more male patients than female in all 5 years. A maximum of 1190 cases was recorded in 2015 and a minimum of 987 cases in the year 2013.

\section{Age group analysis}

Age was categorised into six groups from 0 to 5 years, 6-12 years, 13-20 years, 21-40 years, $41-60$ years and 61 years and above.

Figure 1 shows that the maximum number of cases during all 5 years were from the age group of 21 to 40 years and least were from the age group of 6 to 12 years.

In 5 years, a total of 4189 cases of diarrhoea and gastroenteritis of presumed infectious origin were recorded followed by 680 cases of typhoid fever (table 1). Comparatively lesser females had diarrhoea and gastroenteritis of presumed infectious origin in all 5 years.

\section{Deaths indexed from 2012 to 2016}

From 2012 to 2016, a total of 62/73 (85\%) deaths were recorded under diarrhoea and gastroenteritis of presumed infectious origin (figure 2).

\section{DISCUSSION}

The current study showed the trend of intestinal infectious diseases from 2012 to 2016 . Of the total 5317 cases, $57.7 \%$ were males. A previous study was conducted in the state of Hyderabad, the sixth most populous urban agglomeration in India, where the sex composition of the population is $1: 1{ }^{6}$, showed equal sex distribution of the disease. ${ }^{7}$ In a study conducted in west central India, Maharashtra, there was a preponderance of hepatitis, typhoid and acute diarrheal diseases in males. ${ }^{8}$ Another study conducted in a hilly state of north-east India, Tripura, ${ }^{9}$ reported a majority of female cases in the age group of 19 to 59 years.

Apart from these comparative findings, other results showed that $27 \%$ were in the reproductive age group of 21 to 40 years followed by $23.4 \%$ from the economically productive age group of 41 to 60 years, $16.1 \%$ elderly population of above 61 years and $15.5 \%$ children under 5 years. The least were in the school age group of 6 to 12. Cholera is still an important public health concern in developing countries. ${ }^{8}$ Four cases of cholera were reported in 2016. From 2012 to 2014 there was a gradual decrease in typhoid cases and it then shot up to 179 in 2015 and decreased to 114 in 2016. There was an increase in the cases of enterocolitis due to clostridium difficile and shigellosis from 2012 to 2015 and slight decrease in 2016. Amoebic dysentery and amoebic liver abscess decreased from 2012 to 2016. There was a constant increase in diarrhoea and gastroenteritis of presumed infectious origin from 2012 to 2015 with slight decrease in 2016.

The trend showed a decrease in mortality rate due to intestinal infectious diseases from 2012 to $2014(2.06 \%$, $1.51 \%, 0.57 \%$ respectively) and increased to $1.59 \%$ in 2015 and $1.11 \%$ in 2016. In total 73 deaths were recorded of which $60.3 \%$ were males and $39.7 \%$ females: $85 \%$ of deaths were due to diarrhoea and gastroenteritis of presumed infectious origin.

Even after the progress made in controlling mortality relating to diarrheal disease, the burden of the disease 
Table 1 Annual analysis of intestinal infectious diseases from 2012 to 2016 by ICD-10 classification

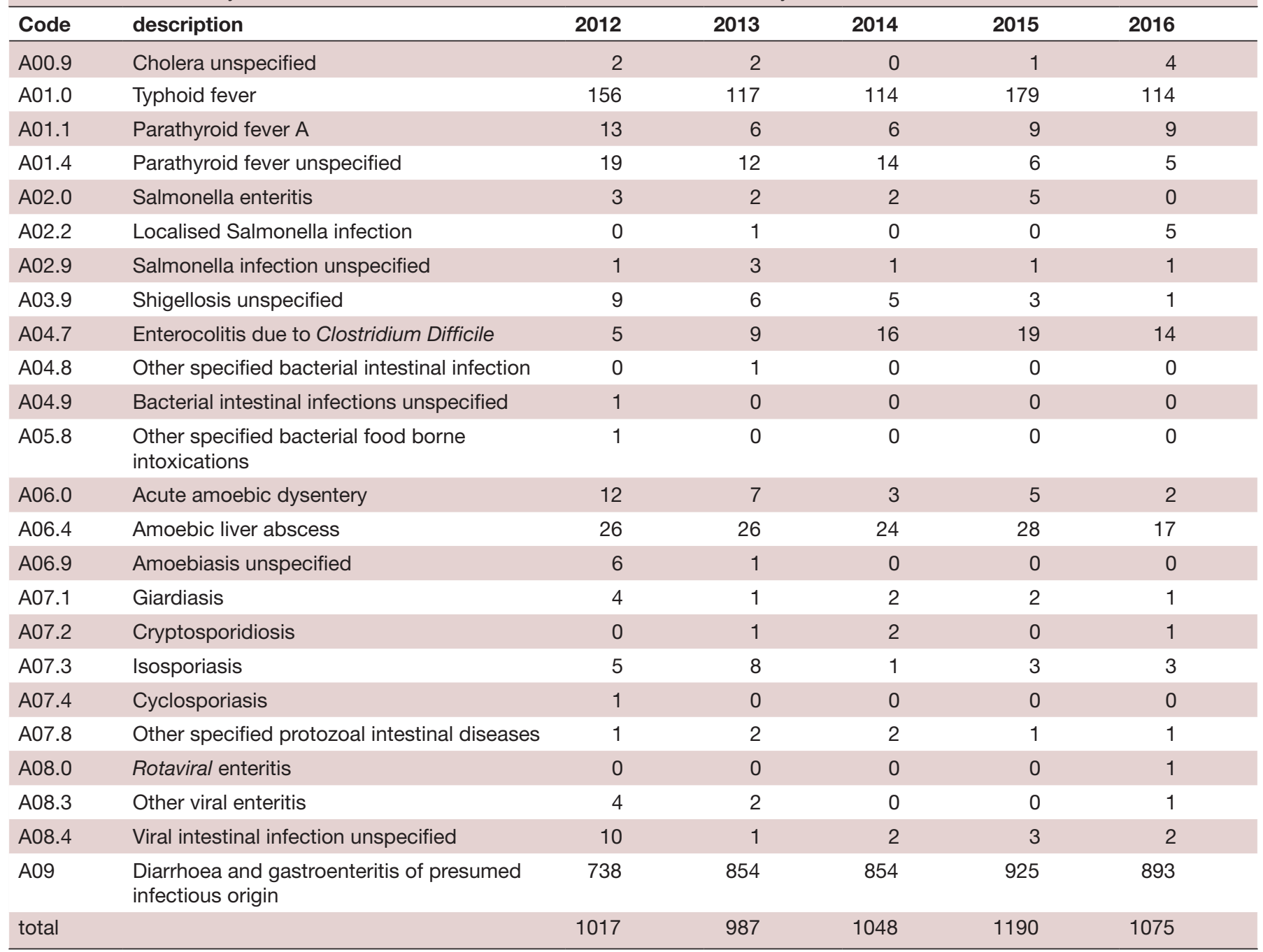

still remains unacceptably high in developing countries and studies have found that the most important cause for severe gastroenteritis in children in developing countries is Rotavirus. ${ }^{10}$ In situations with the highest burden of disease, health information and laboratory systems are not adequately equipped to identify and record aetiology specific information. In our study, it was observed that most of the diseases were recorded and coded as unspecified including diarrhoeas and gastroenteritis of presumed infectious origin where aetiology is not specified.

Total death cases from 2012 to 2016: categorized

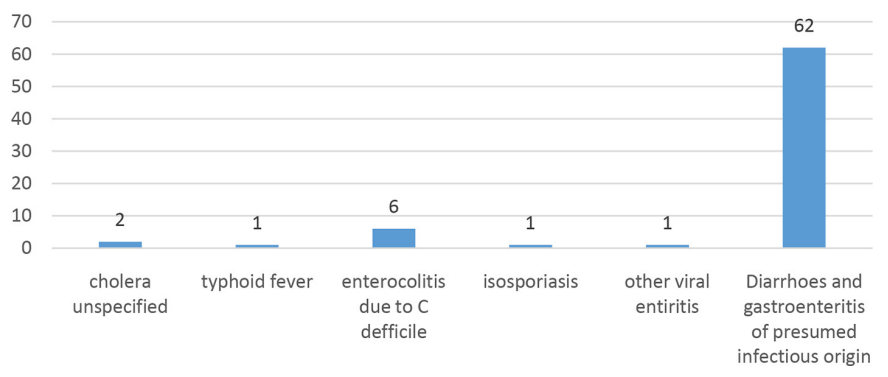

Figure 2 Causes of death 2012 to 2016.

\section{CONCLUSION}

Conclusions drawn from healthcare data are very important for understanding the public health situation of any region/area/country. Although there is economic growth in India, the growth in the detection and control of much prevalent diarrhoea and gastroenteritis is slow. An accurate analysis of morbidity trends of diseases provides an efficient tool for the health planners for the formulation of preventive programme and policies. The findings of the current study point towards an urgent need of health education among the population regarding infectious intestinal diseases and to redesign health promotion and preventive strategies for addressing these problems.

It is suggested that care should be taken for standard documentation practices and accurate reporting system. Electronic health records and standard coding practices can help in accurate health reporting with due consideration for confidentiality and statutory rules.

Competing interests None declared.

Patient consent for publication Not required.

Provenance and peer review Not commissioned; externally peer reviewed. 
Open access This is an open access article distributed in accordance with the Creative Commons Attribution Non Commercial (CC BY-NC 4.0) license, which permits others to distribute, remix, adapt, build upon this work non-commercially, and license their derivative works on different terms, provided the original work is properly cited, appropriate credit is given, any changes made indicated, and the use is non-commercial. See: http://creativecommons.org/licenses/by-nc/4.0/.

\section{REFERENCES}

1. John TJ, Dandona L, Sharma VP, et al. Continuing challenge of infectious diseases in India. Lancet 2011;377:252-69.

2. WHO. An integrated approach to communicable disease surveillance. Epidemiolog Bull, PAHO 2000;13:1-16.

3. WHO. Global status report on non-communicable diseases, 2010. Available: https://www.who.int/nmh/publications/ncd_report_full_en. pdf

4. Sustainable development goals. United Nations "Sustainable Development Goals" Knowledge platform. Available: https://www. un.org/sustainabledevelopment/development-agenda/ [Accessed 28/02/2019].

5. World Health Organization. International statistical classification of diseases and related health problems. 1 and 2. 10th Revision. Geneva: World Health Organization, 2006.

6. Directorate of Economics and Statistics, Government of Hyderabad. Statistical year book 2017. Available: https://www.telangana.gov.in/ PDFDocuments/Statistical-Year-Book-2017.pdf

7. Kalyani D, Shankar K. Assessment and seasonal variations of communicable diseases: 3 year study. Int J Res Med Sci 2016;4:1186-92.

8. Gaikwad L, Haralkar S. Morbidity profile and seasonal variations of communicable diseases among hospitalized patient in a teaching hospital Solapur (Maharashtra), India. Int J Med Sci 2015;2:13-16.

9. Datta A, Nag K, Karmakar N, et al. A study to assess common morbidity pattern of an urban population of Tripura. Int $J$ Community Med Public Health 2017;4:4613-6.

10. Kotloff KL, Nataro JP, Blackwelder WC, et al. Burden and aetiology of diarrhoeal disease in infants and young children in developing countries (the global enteric multicenter study, GEMs): a prospective, case-control study. The Lancet 2013;382:209-22. 